\title{
Challenges in Diagnosing and Treating Obstructive Sleep Apnoea in Children
}

\author{
Refika Ersu \\ Marmara University, Istanbul, Turkey
}

DOl: https://doi.org/10.17925/ERPD.2018.4.1.23

\section{Keywords}

Diagnosis, obstructive sleep apnoea syndrome (OSAS), sleep disordered breathing (SDB), treatment

Disclosure: Refika Ersu has no conflicts of interest to declare in relation to this article. She is a member of the journal's editorial board.

Review process: This article is an opinion piece and has not been submitted to external peer reviewers.

Authorship: The named author meets the International Committee of Medical Journal Editors (ICMJE) criteria for authorship of this manuscript, takes responsibility for the integrity of the work as a whole, and has given final approval to the version to be published.

open Access: This article is published under the Creative Commons Attribution Noncommercial License, which permits any noncommercial use, distribution,

adaptation, and reproduction provided the original author and source are given appropriate credit.

(c) The Author 2018.

Received: 17 August 2018

Published Online: 5 September 2018

Citation: European Respiratory \& Pulmonary Diseases. 2018;4(1):23-4

Corresponding Author: Refika Ersu, Marmara University, Division of Pediatric Pulmonology, Fevzi Çakmak Mah., Mimar Sinan Cd., No: 41 Üst Kaynarca, Pendik, Istanbul, Turkey. E: rersu@yahoo.com

Support: No funding was received for the publication of this article.
The European Respiratory Society (ERS) taskforce on the diagnosis and management of obstructive sleep disordered breathing (SDB) in childhood, defined obstructive SDB as "a syndrome of upper airway dysfunction during sleep, characterised by snoring and/or increased respiratory effort secondary to increased upper airway resistance and pharyngeal collapsibility". ${ }^{1}$ In this statement, two technical definitions of obstructive sleep apnoea syndrome (OSAS) were proposed based on the available literature:

- Definition 1: obstructive apnoea-hypopnoea index (AHI; obstructive and mixed apnoeas and hypopnoeas per hour of total sleep time) $\geq 2$ episodes/hour; or an obstructive apnoea index (obstructive apnoeas per hour of total sleep time) $\geq 1$ episode/hour in the presence of SDB symptoms, adenotonsillar hypertrophy with or without obesity and no other abnormalities predisposing to OSAS.

- Definition 2: presence of SDB symptoms in combination with AHI $\geq 1$ episode/hour.

Authors noted that the latter definition has been applied in most published studies. Obstructive sleep apnoea is common in children with a prevalence of $1-5 \%$ and children at risk need to be diagnosed and treated in a timely manner because of health consequences on neurocognitive, cardiovascular and metabolic systems. ${ }^{1,2}$ Children with OSAS also have increased healthcare utilisation which decreases following adenotonsillectomy. ${ }^{3,4}$

\section{Challenges in diagnosis}

The clinical suspicion for OSAS is most often raised by parental report of specific symptoms, and/or abnormalities identified by physical examination, which predispose to upper airway obstruction (e.g., adenotonsillar hypertrophy, obesity, craniofacial abnormalities, neuromuscular disorders). Following recognition of the child who is at risk of OSAS based on the presence of relevant symptoms, an objective tool should be applied to determine SDB severity and confirm whether the definition of OSAS is fulfilled. ${ }^{5}$ According to the American Academy of Pediatrics Clinical Practice Guideline on childhood OSAS, the attended, in-laboratory, overnight polysomnography (PSG) (preferably video-PSG) is considered the gold standard method. ${ }^{6}$ However, PSG is a cumbersome, expensive and resource-intensive diagnostic procedure and is not widely available, especially in resource-limited countries. Additionally, PSG-derived respiratory parameters, such as the AHI and the number of desaturations and arousals, have not been found to reliably predict the degree of physical or psychological impairment in children with SDB. ${ }^{78}$

Nocturnal oximetry, respiratory polygraphy and standardised questionnaires are alternative diagnostic tools especially in the non-obese, otherwise healthy child with adenotonsillar hypertrophy who snores. Nocturnal oximetry studies have a high specificity but low sensitivity in the diagnosis of paediatric OSAS. ${ }^{9}$ Three or more clusters of desaturation events $\geq 4 \%$ and at least three desaturations to $<90 \%$ are considered abnormal. ${ }^{10}$ Although the rate of false-negative or inconclusive results is high, it may help to prioritise the treatment in settings where PSG is not available. Respiratory polygraphy studies are PSGs without the electroencephalography, electromyography, and electrooculography data. Although some centres have reported good 
agreement with PSG, AHI may be under- or overestimated in these studies due to missed hypopnoeas resulting in arousals but not desaturation or overestimation of hours of sleep. ${ }^{11-3}$

Ambulatory PSG or polygraphy studies are routinely used in adults to diagnose OSAS. Recently, more studies have been published that evaluate the value of these studies to diagnose SDB even in young children. They are a less expensive and labour-intensive alternative to in-lab PSGs and may also be more representative of the child's typical night's sleep at home. However, more studies are needed to evaluate the association of parameters derived from these studies to the health outcomes of children with SDB.

\section{Challenges in treatment}

ERS guidelines recommend treatment in children with an $\mathrm{AHI} \geq 5$ episodes/hour. In children with $\mathrm{AHI}>1$ but $\leq 5$ episodes/hour, treatment may be beneficial especially in the presence of comorbidities. ${ }^{1}$ ERS guidelines also recommend a stepwise treatment approach starting with the least invasive method and combining different treatment modalities until the resolution of OSAS. ${ }^{1}$ Previously, children with typical OSAS had adenotonsillar hypertrophy and failure to thrive; the main treatment modality for these children was adenotonsillectomy. However, with the increasing childhood obesity, more children diagnosed with OSAS are obese. The Childhood Adenotonsillectomy Trial (CHAT), a randomised controlled trial that compared the effects of adenotonsillectomy versus watchful waiting in children with mild OSAS, did not find any significant improvements in cognitive function after treatment, although there were improvements in behaviour, symptoms and quality of life. ${ }^{14}$ Also, this study confirmed the findings of the previous studies which showed that children with obesity are less likely to improve with surgery.
Sleep endoscopy may help to identify the levels of upper airway obstruction, especially in children with complex conditions and help to direct therapy to improve the surgical outcomes. ${ }^{15}$

Positive airway pressure (PAP) is the preferred therapy of adults with OSAS. Continuous PAP may be considered the first-line of treatment in children when surgery is considered high risk or contraindicated, or for children with residual OSAS, craniofacial anomalies or obesity. However, compliance is an issue with PAP treatment, and the data suggest that compliance rates are approximately $65-70 \%{ }^{16,17}$ Weight loss is effective in obese adolescents; however, weight loss strategies may not always be successful in community settings. ${ }^{18,19}$ Anti-inflammatory treatment with nasal corticosteroids and/or oral montelukast may be effective in children with OSAS since these children have increased expression of leukotriene C4 synthase as well as leukotriene receptors 1 and 2 in tonsillar lymphocytes compared with controls. ${ }^{20}$ Treatment with nasal steroids and/or montelukast may reduce adenoidal size and treatment with these agents has shown improvement in children with mild to moderate OSAS. ${ }^{1}$ However, the duration and long-term benefit of this treatment is not yet clear.

Diagnosing and treating children with OSAS is not always straightforward. Not all children with OSAS manifest complications of SDB. We need to develop tools that are easily accessible and associated with the outcomes. This will increase our ability to recognise at-risk groups and prioritise treatment of paediatric OSAS for those who are at increased risk. There are only few studies that combine different treatment modalities to improve treatment outcomes. . $122^{122}$ Individualising and combining different modalities may improve the treatment of these children to prevent long term consequences that are associated with SDB. $\square$
1. Kaditis AG, Alonso Alvarez ML, Boudewyns A, et al Obstructive sleep disordered breathing in 2- to 18-yearold children: diagnosis and management. Eur Respir J. 2016;47:69-94.

2. Lumeng JC, Chervin RD. Epidemiology of pediatric obstructive sleep apnea. Proc Am Thorac Soc. 2008;5:242-52.

3. Tarasiuk A, Greenberg-Dotan S, Simon-Tuval T, et al. Elevated morbidity and health care use in children with obstructive sleep apnea syndrome. Am J Respir Crit Care Med. 2007;175:55-61.

4. Tarasiuk A, Simon T, Tal A, et al. Adenotonsillectomy in children with obstructive sleep apnea syndrome reduces health care utilization. Pediatrics. 2004;113:351-6.

5. Joosten K, Larramona H, Miano S, et al. How do we recognize Joosten K, Larramona H, Miano S, et al. How do we recognize
the child with OSAS? Pediatr Pulmonol. 2017:52:260-71. the child With OSAS? Pediatr Pulmonol. 2017;52:260-7
Marcus CL, Brooks L, Draper KA, et al. Diagnosis and 6. Marcus $\mathrm{CL}$, Brooks $\mathrm{L}$, Draper $\mathrm{KA}$, et al. Diagnosis and
management of childhood obstructive sleep apnea syndrome. Pediatrics. 2012;130:e714-55.

7. Gozal D, Kheirandish-Gozal L, Bhattacharjee R, et al. Neurocognitive and endothelial dysfunction in children with obstructive sleep apnea. Pediatrics. 2010;126:e1161-7.

8. Gozal D, Kheirandish-Gozal L. New approaches to the diagnosis of sleep disordered breathing in children. sleep Med. 2010;11:708-13.
9. Nixon GM, Brouillette RT. Diagnostic techniques for obstructive sleep apnoea: is polysomnography necessary? Paediatr Respir Rev. 2002;3:18-24

10. Kaditis A, Kheirandish-Gozal L, Gozal D. Algorithm for the diagnosis and treatment of pediatric OSA: a proposal of two pediatric sleep centers. Sleep Med. 2012;13:217-27.

11. Alonso Alvarez ML, Terán Santos J, Cordero Guevara JA, et al. Reliability of respiratory polygraphy for the diagnosis of sleep apnea-hypopnea syndrome in children. Arch Bronconeumol. 2008;44:318-23.

12. Tan HL, Gozal D, Ramirez HM, et al. Overnight polysomnography versus respiratory polygraphy in the diagnosis of pediatric obstructive sleep apnea. Sleep. 2014;37:255-60

13. Alonso-Álvarez ML, Terán-Santos J, Ordax Carbajo E, et al. Reliability of home respiratory polygraphy for the diagnosis of Reliability of home respiratory polygraphy for the
sleep apnea in children. Chest. 2015:147:1020-8.

14. Marcus CL, Moore RH, Rosen CL, et al. A randomized trial of adenotonsillectomy for childhood sleep apnea. N Eng/ J Med. 2013;368:2366-76

15. Boudewyns A, Saldien V, Van de Heyning P, Verhulst S. Drug induced sedation endoscopy in surgically naive infants and children with obstructive sleep apnea: impact on treatment decision and outcome. Sleep Breath. 2018;22:503-10.

16. Uong EC, Epperson M, Bathon SA, et al. Adherence to nasal positive airway pressure therapy among school-aged children and adolescents with obstructive sleep apnea syndrome. Pediatrics. 2007;120:e1203-11.

17. O'Donnell AR, Bjornson CL, Bohn SG, et al. Compliance rates in children using noninvasive continuous positive airway pressure. Sleep. 2006;29:651-8.

18. Verhulst SL, Franckx H, Van Gaal L, et al. The effect of weight loss on sleep-disordered breathing in obese teenagers. Obesity (Silver Spring). 2009;17:1178-83.

19. Alonso-Álvarez ML, Terán-Santos J, Navazo-Egüia Al, et al. Treatment outcomes of obstructive sleep apnoea in obese community-dwelling children: the NANOS study. Eur Respir J. 2015:46:717-27.

20. Tsaoussoglou M, Hatzinikolaou S, Baltatzis GE, et al. Expression of leukotriene biosynthetic enzymes in tonsillar tissue of children with obstructive sleep apnea: a prospective nonrandomized study. JAMA Otolaryngol Head Neck Surg. 2014;140:944-50.

21. Guilleminault C, Monteyrol PJ, Huynh NT, et al. Adenotonsillectomy and rapid maxillary distraction in pre-pubertal children, a pilot study. Sleep Breath. 2011;15:173-7.

22. Kaditis A, Lévy P. Focus on prevention and treatment of obstructive sleep disordered breathing in childhood. Eur Respir J. 2015:46:615-8. 